319-331), those from other sources being given in brackets.

Other sources used include the "Henry Draper Catalogue", or its manuscript revision by Dr. H. Knox-Shaw, and the "Albany General Catalogue". Among magnitudes frequently quoted some very large errors have been found, and in nearly all cases where an accurate photographic and visual magnitude is available the colour index agrees to within $0 \cdot 1$ magnitude with the mean value for the spectral type. For this reason, when the "Henry Draper Catalogue" gives a photometric magnitude to two decimals, greater accuracy is obtained in deriving the photographic magnitude from the visual by applying the colour index than by using a rough photographic magnitude. Some examples of this are given, and it is pointed out that in the "Henry Draper Catalogue" the error of the photographic magnitude for some of the bright stars is quite serious. It is suggested that there must be many stars within a distance of 10 parsecs for which the determination of absolute magnitude is rendered erroneous more by error in apparent magnitude than in parallax, and the conclusion is that a programme for determining the magnitudes of stars on parallax lists should be initiated.

\section{THE MEDICAL RESEARCH COUNCIL}

\section{REPORT FOR 1948-50}

$\mathrm{T}$ HE successive reports of the Medical Research Council have always been welcome and valuable contributions to literature on the planning and progress of medical research. They have, as the Council's programme has grown and expanded, directed our minds through a maze of problems the inter-relations and complexities of which increase as the work of teams and individual workers extends and deepens our knowledge. It is not surprising that those who write these reports are faced with the problem of how to present the mass of material that nowadays is available and that changes in the form of the report have been adopted. These changes are apparent in the Council's latest account of its activities, "Report of the Medical Research Council for the Years 1948-50"*.

This valuable document records the Council's work since its war-time short-term researches came to an end. During the Second World War the Council had found that studies of practical problems generally led to valuable solutions, provided that substantial fundamental knowledge was already available; but that lack of sufficient basic knowledge limited and delayed the help that could be given. The Council has therefore wisely decided to apportion its resources between the search for basic knowledge and the study of practical problems which need to be solved at the present time.

Not all the researches in progress are mentioned in this report. Instead, a series of essays is given on the general trends of the work in progress, with summaries of the results, together with lists of the specific problems under investigation in each of the Council's many departments. The report also gives the personnel of each of these departments and-a valuable innovation-references, in a single list, to the papers

* Committee of the Privy Council for Medical Research. Report of the Medical Research Council for the Years 1948-1950. (Cmd. 8387.) Pp. iv +247. (London: H.M.S.O., 1951.) 68. 6d. net. published by members of the Council's staff. The publication is therefore a general account of the Council's work which summarizes, in effect, the present state of knowledge of each of the subjects considered, together with a valuable bibliography by means of which particular aspects of all this work can be followed up. Many will prefer this type of report to preceding ones in which the work of the separate departments has been given in greater detail.

The breadth of the Council's programme is indicated by the headings under which its work is epitomized. These are: chemotherapy and antibiotics, tuberculosis, virus diseases, $Q$ fever, cortisone and adrenocorticotrophic hormone, methonium compounds, biological standardization, biochemical research, biological aspects of atomic physics, cancer research, blood groups and blood transfusion, tropical medicine, occupational health and undernutrition. From the summaries of work given under each of these headings, one can gain a valuable conception of the modern status of knowledge in each of these important fields. Separate reports dealing with the work done in some of them have already been published. An outstanding example is the remarkable publication entitled "Studies of Undernutrition, Wuppertal, 1946-9"*, which records the investigations made by the members. of the Department of Experimental Medicine, University of Cambridge, and associated workers, on part of the population of Wuppertal and on German prisoners-of-war repatriated from the U.S.S.R. No one who is interested in this general matter of undernutrition, whether his interest be medical, sociological or political, can afford to miss this contribution to the problem. One wonders, while reading some parts of the report, especially the section that deals with emotional and behavioural reactions, how widely some of the symptoms described could be discovered in the United Kingdom at the present time.

This, however, is only one of the many special reports and memoranda issued by the Medical Research Council, all of which are evidence of the great services of its former secretary, Sir Edward Mellanby, whose retirement in 1949 was so universally regretted. In the report of the Council for 1948-50 there is a just tribute to his work and also to his personal research. Fortunately, neither his great experience and personal research abilities, nor those of Lady Mellanby, are lost to the Council, for Sir Edward remains as the director of the Council's Nutrition Building and Lady Mellanby is also working there.

To Sir Harold Himsworth, who succeeds to the secretary's duties and opportunities, Sir Edward leaves an organization of which the vigour and breadth of outlook are unrivalled. In it the spirit of its first secretary, Sir Walter Fletcher, still lives to inspire and encourage every member of the staff and to challenge succeeding secretaries to excel an achievement which owed much to Sir Walter's rare personality and outstanding gifts. In these days, when the Council's work has grown so much, it may be difficult for any man to keep the personal contacts with each member of the staff which were a feature of Fletcher's regime; but the same spirit will be there, the same drive for human health and the same underlying concern for the welfare of mankind.

G. LAPAgE

- Medical Research Council. Spectal Report Series No. 275 : Studies of Undernutrition, Wuppertal, 1946-49. Pp. iv +404+62 plates. (London: H.M.S.O., 1951.) 128. 6d. net. 